\title{
EQUITY-PREMIUM PUZZLE: EVIDENCE FROM BRAZILIAN DATA*
}

\author{
Rubens Penha Cysne ${ }^{\S}$
}

\begin{abstract}
RESUMO
Este trabalho usa dados brasileiros do período 1992:1-2004:2 e dois diferentes métodos (aproximação sob a hipótese de lognormalidade e calibração) para avaliar a existência de um "equity-premium puzzle" no Brasil. Em contraste com alguns trabalhos prévios da literatura nacional, conclui-se que o modelo usado por Mehra and Prescott (1985), seja com preferências aditivas ou recursivas, não é capaz de gerar o prêmio de risco observado na economia brasileira. A segunda contribuição do trabalho é chamar a atenção para o fato de que a função utilidade calculada sob a hipótese de aproximação discreta do espaço de estados pode não existir se os dados (como é o caso no Brasil) implicarem a existência de estados nos quais taxas altamente negativas de crescimento do consumo são alcançadas com probabilidade demasiado elevadas. Este fato é particularmente importante quando se tenta utilizar parâmetros de aversão ao risco altos o suficiente para gerar o prêmio de risco inerente ao caso brasileiro.
\end{abstract}

Palavras-chave: prêmio de risco, precificação de ativos, utilidade recursiva, prêmio de risco no Brasil, "equitypremium puzzle".

\begin{abstract}
This paper uses 1992:1-2004:2 quarterly data and two different methods (approximation under lognormality and calibration) to evaluate the existence of an equity-premium puzzle in Brazil. In contrast with some previous works in the Brazilian literature, I conclude that the model used by Mehra and Prescott (1985), either with additive or recursive preferences, is not able to satisfactorily rationalize the equity premium observed in the Brazilian data. The second contribution of the paper is calling the attention to the fact that the utility function calculated under the discrete-state approximation may not exist if the data (as it is the case with Brazilian time series) implies the existence of states in which high negative rates of consumption growth are attained with relatively high probability. This fact is particularly important when the researcher tries to work with high risk-aversion parameters in order to generate high risk premia.
\end{abstract}

Key words: equity premium, puzzle, Brazil, recursive preferences, asset pricing.

JEL classification: G12, E40.

\footnotetext{
* I am thankful to Marco Bonomo, to the participants of workshops at the Department of Economics of the University of Chicago, of the Graduate School of Economics of the Getulio Vargas Foundation and of the 2005 Meeting of the ANPEC (Associação Nacional de Centros de Pós-Graduação em Economia) for their comments. The usual disclaimer applies.

$\S$ Professor of Economics at the Graduate School of Economics of the Getulio Vargas Foundation (EPGE/FGV) and a Visiting Scholar at the Department of Economics of the University of Chicago. Endereço para contato: Escola de Pós Graduação em Economia da Fundação Getulio Vargas - Praia de Botafogo 190,11ªndar - Rio de Janeiro - tel: 21 25595871. E-mail: rubens@ fgv.br.
}

Recebido em junho de 2005. Aceito em março de 2006. 


\section{INTRODUCTION}

It has been now twenty years since the seminal paper by Mehra and Prescott (1985) raised the question of the "Equity-Premium Puzzle" (henceforth, EPP).

This is the name economists give to the fact that basic representative-agent models of asset pricing (e.g., Lucas, 1978; Breeden, 1979; and Mehra and Prescott's, 1985, adaptation of Lucas' (1978) work ${ }^{1}$ ) have not been able to satisfactorily rationalize the fact that US real returns on stocks have been, between 1889 and 1978, about six percent per year higher than those on T-Bills.

The title Mehra and Prescott used in their (now) famous article generated a curious semantic herd behavior in the profession. What should be just one more case of the universal problem regarding the failure of a certain model to explain a certain data set was named a "puzzle". Following the trend, several other macroeconomically disappointing ${ }^{2}$ exercises of statistically unsatisfactory analysis, ${ }^{3}$ pertaining to the domain of what is usually dubbed "calibration", were also given the name "puzzle".

Among these is the "risk-free rate puzzle", introduced in the literature by Weil (1989). This puzzle relates to the (low) long-run level of Treasury returns in the United States, when compared to those implied by Mehra and Prescott's-type models.

Consistently with the underlying time frame of their model, Mehra and Prescott used US long-term data. Here, because long-term data is not available for Brazil, I follow Sampaio (2002), Bonomo and Domingues (2002), Alencar (2002) and Issler and Piqueira (2000, 2002) and use short-term data. Relatively to these previous works, this work uses data of a more recent period.

The economic reasoning behind the first two puzzles cited above is as follows. Assets paying higher returns should do it, in equilibrium, according to the basic asset-pricing models previously mentioned, based on the fact that they present a higher covariance with the consumption stream of the representative agent. However, the empirical data for the US has shown that, under the values of the risk-aversion and of the time-discount parameters which are considered to be reasonable, stock returns's covariance with consumption is not sufficiently greater than that of Treasury Bills, in order to explain the observed difference in their yields. This is what is behind the EPP.

To explain the high spread between stocks and bonds, one needs values of the risk-aversion parameter that are considered too high. Assuming standard utility functions, in which the risk aversion equals the inverse of the elasticity of substitution, this is to say that agents should highly dislike growth. However, if this were true, the necessary risk-free rates to explain the amount of saving in the US, an economy in which real per-capita consumption growth reaches almost two percent per year, should be much higher than the historical one percent per year observed in the data. This leads to Weil's "risk-free rate puzzle" to which I have referred above.

Such puzzles emerge under the assumptions of complete markets, costless asset trading, and that consumer preferences can be represented by the standard utility function used in macroeconomics. Explanations of the puzzles, therefore, can always be made by leaving aside one or more of these three assumptions. There must be, though, consistent support from the empirical evidence in doing so.

\footnotetext{
To be detailed later in this paper. These models are usually denominated CCAPM (Consumer Capital Asset Pricing Models). Because the model does not explain the data.

See, e.g., Browning, Hansen and Heckman (1999). Of course, the criticism (regarding "calibrations") extends to the results reported in this paper.

4 For instance, one could abandon the hypothesis of costless trading and argue that the equity premium can be explained by the fact that trading stocks is much more costly than buying Treasury Bills. However, the empirical evidence about this assumption, at least in the US, is not conclusive.
} 
A considerable amount of academic research has been developed attempting to solve these puzzles. The explanations include simply denying the existence of a puzzle (see, e.g., Cecchetti and Mark, 1990), or arguments based on: i) recursive utility (Epstein and Zin, 1991); ii) habit formation (e.g., Constantinides, 1990; Campbell and Cochrane, 1999); iii) idiosyncratic risk (Heaton and Lucas, 1996; Constantinides and Duffie, 1996); iv) probability of a large drop in consumption (Rietz, 1988); v) borrowing constraints (Davis and Willen, 2000); vi) liquidity premium (Bansal and Coleman, 1996) and; vii) changes in tax rates (McGrattan and Prescott, 2001).

In the present work, the only departure from the assumptions outlined in Mehra and Prescott (1985) that I shall consider regards the modification of the utility function to allow for Kreps-Porteus (1978) preferences, in the line of Epstein and Zin (1991).

In Brazil, some papers concerning, among other subjects, the possible existence of these two puzzles, have been conveniently collected in a book edited by Bonomo (2002). In the second part of this book, three different techniques have been used by several authors in order to assess if the CCAPM models could explain the respective data generated by the Brazilian economy. Among these, Sampaio (2002) follows the basic methodology used by Mehra and Prescott. Bonomo and Domingues (2002) innovate by modeling the consumption series using a Markov-switching model and also by using a Kreps-Porteus (1978) utility function. Alencar (2002) uses the approach of Hansen and Jagannathan (1991), interpreting the equity premium puzzle in terms of the "market price of risk" generated by the data, and constructing volatility bounds. Finally, Issler and Piqueira (2000 and 2002), approach the problem by testing the Euler equations implied by three different models.

A common fact about these works is that they find either that "there is no EPP in Brazil (Issler and Piqueira, 2000, p. 233; Bonomo and Domingues, 2002, p. 116; and Sampaio, 2002, p. 99) or that there is a puzzle, but it less intense than the one which emerges with data related to the US (Alencar, p. 152). ${ }^{6}$ Yoshino and Catalão (2004) also follow this line of conclusion.

When one concentrates solely on the basic assumptions of the model underlying these empirical analyses, such a conclusion of nonexistence of an equity-premium puzzle is intriguing ${ }^{7}$. Indeed, it is hard to argue that Brazil would be any closer to complete markets or costless stock trading than the United States, United Kingdom, Japan, Germany, and France, just to cite some countries where the empirical failure of CCAPM models has been documented ${ }^{8}$ (see, e.g., Allais and Nalpas, 1999; Iwata, 1996; Canova and Nicolo, 1995; Mehra, 2003; or Santomero, 2001).

These contrasting results obtained by the authors using Brazilian data and authors using other sets of data suggest that new insights into the problem can be rewarding. Proceeding with this examination is the main motivation for the present paper.

I pursue this objective by initially reassessing if the Mehra and Prescott's model, either under the usual CRRA utility or under recursive utility, can indeed be a reasonable model to explain the EPP, as claimed by Sampaio (2002), Bonomo and Domingues (2002), Issler and Piqueira (2000, 2002) and Yoshino and Catalão (2004). Regarding the EPP, my conclusions contrast with those of these authors. I find that there is an EPP in Brazil. Moreover, I have found no evidence of "an inverted risk-free puzzle”, as pointed out by Bonomo and Domingues (2002). Though not able

5 In the case on non-seasonally adjusted data.

6 Soriano, though, arrives at this milder conclusion by considering seasonally adjusted data. The remaining works, including the results I report here, were based in nonseasonally adjusted data.

7 However, one must observe that not all dimensions of the Brazilian data turn out to be explainable by the CCAPM. Bonomo and Domingues (2002), for instance find an inverted puzzle regarding the riskless rate and, moreover, report that they have not been able to reproduce the high standard deviation of the risky return.

8 As pointed out by Mehra (2003), the United States, the United Kingdom, Japan, Germany, and France account for more than 85 percent of global equity value. 
to explain the equity premium, the model can satisfactorily generate the risk-free rates of interest prevailing in Brazil.

The remaining of this work proceeds as follows. Sections 2 and 3 present the basic model and the conditions for the existence of an expected utility. Section 4 is used to discuss the new data set from which I derive new results, and to compare it with the data sets used by other authors. Section 5 displays new empirical outcomes, initially in the form of approximations under assumptions of lognormality and, next, as the asset returns implied by the simulations. Given the contrasting evidence regarding the empirical results of this work and of its predecessors, Section 6 offers tentative explanations for such discrepancies. Section 7 recalculates the simulations under the assumption of recursive utility. Section 8 concludes.

\section{THE BASIC MODEL}

Mehra and Prescott (1985) have adapted Lucas's (1978) pure-exchange model by assuming that consumption growth, rather than consumption itself, follows a first-order Markov process. This adaptation aims at capturing possible nonstationarities of the real per-capital consumption series.

Below, I describe the well known CCAPM model using initially an Arrow-Debreu structure with contingent claims all traded at time 0 . Next, I assume a Markovian structure of endowments and use the pricing sequence previously obtained to price one-period Arrow securities in a sequential-trading structure.

There are several identical consumers in the economy. A representative consumer maximizes the discounted utility $(U)$ of consumption $(c):^{9}$

$$
U(c)=E_{0} \sum_{t=0}^{\infty} \beta^{t} u\left(c_{t}\right), \quad 0<\beta<1
$$

or, given the assumption of a finite number of states, and with $\lambda^{t}$ standing for the history of states till time $t$ :

$$
U(c)=\sum_{t=0}^{\infty} \sum_{\lambda^{t}} \beta^{t} u\left(c_{t}\left(\lambda^{t}\right)\right) \pi_{t}^{0}\left(\lambda^{t}\right)
$$

subject to the constraint:

$$
\sum_{t=0}^{\infty} \sum_{\lambda^{t}} q_{t}^{0}\left(\lambda^{t}\right) c_{t}\left(\lambda^{t}\right) \leq \sum_{t=0}^{\infty} \sum_{\lambda^{t}} q_{t}^{0}\left(\lambda^{t}\right) e_{t}\left(\lambda^{t}\right)
$$

Above, $\beta$ stands for the time-discount parameter, $E_{t}$ for the expectation conditional on the information available at time $t, q_{t}^{0}$ for the time-zero price of a security promising to pay one unit of consumption at time $t, \pi_{t}^{0}$ for the conditional probability (on the information available at time zero) of having the history $\lambda_{t}$ and $e_{t}$ for the endowment at time $t$. Equation (2) uses the fact that

9 By assumption $\lim _{c \rightarrow 0} u(c)=\infty$ and $u(c)$ is concave. 
the linear functional defined in the commodity space of the problem has a dot product representation. $^{10}$

Make $1+g_{t+1}=\frac{e_{t+1}}{e_{t}}$, the aggregate endowment growth in period $t+1$. Endowments are assumed to be governed by a Markov process. In equilibrium, endowments will also be equal to the real per-capita consumption growth.

Assume that:

$$
u(c)=\frac{c^{1-\gamma}-1}{1-\gamma}, \quad 0<\gamma<\infty
$$

In the present description of the model, at time $t_{0}$ households trade claims on the time $t$ consumption good at all nodes $\lambda^{t}$. After $t_{0}$ no further trade occurs. There are no enforcement- or information-related incentive problems.

The equilibrium allocations in this economy are equivalent to those of an economy with sequential trading. In particular, the allocations at each point in time depend only on the realized aggregate endowment. It is also assumed that the necessary and sufficient condition for the existence of the utility function given by Proposition 1 below is satisfied.

Under such circumstances, the price/dividend ratio $Q$ can be easily determined, after a straightforward application of the Kuhn-Tucker theorem (the point of departure of which, in this infinite-dimensional case, is the Hahn-Banach separation theorem).

First, use the auxiliary Lagrangean function to obtain:

$$
q_{t+1}^{t}\left(\lambda^{t}\right)=\beta \frac{u^{\prime}\left(c_{t+1}\left(\lambda^{t+1}\right)\right)}{u^{\prime}\left(c_{t}\left(\lambda^{t}\right)\right)} \pi_{t+1}\left(\lambda^{t+1} \mid \lambda^{t}\right)
$$

This expression gives the time-t price of an asset that pays off 1 if history $\lambda^{t+1}$ comes true, given that $\lambda^{t}$ has happened.

Next, (4) will be used to price an ex-dividend one-period ahead stock, at time $t$.

Because of the Markovian structure that we assume for the endowment process, decisions taken at date $t$ only depend on the state variables at this date, and not on the whole history till date $t\left(\lambda^{t}\right)$. This allows us to work conditionally only on the information set available at time $t$, and only consider the possible states that can be reached at date $t+1$, instead of having to keep track of all previous history $\lambda^{t}$ as in (4).

Call the sequential-trading price of an ex-dividend one-period ahead stock $Q_{t}$. Then, using (4):

$$
Q_{t}\left(\lambda_{t}\right)=\sum_{\lambda_{t+1}} \beta \frac{u^{\prime}\left(c_{t+1}\left(\lambda_{t+1}\right)\right)}{u^{\prime}\left(c_{t}\left(\lambda_{t}\right)\right)}\left(Q_{t+1}\left(\lambda_{t+1}\right)+e_{t+1}\left(\lambda_{t+1}\right)\right) \pi_{t+1}\left(\lambda_{t+1} \mid \lambda_{t}\right)
$$

Dividing both terms by $e_{t+1}$ and using (3) leads to the following expression for the price/dividend relation $P_{t}=Q_{t} / e_{t}$ :

10 Note that with exogenous growth the commodity space cannot be the usual $l_{\infty}$ Following Mehra (1988), the commodity space $L$ here is the normed linear space of infinite sequences of vectors with the $t-t h$ vector indexed by the event $e_{t}=\left(g_{1}, g_{2}, \ldots, g_{t}\right)$

The set of possible period t events is called $\mathrm{E}_{t}$, and has cardinality $n^{t}$. The norm of an element $z \in L$ is given by:

$\|z\|=\sup _{t} \max _{e_{t} \in E_{t}} \mid \frac{z_{t}\left(e_{t}\right)}{y_{t}}$

where $y_{t}=y_{0}, g_{1}, g_{2}, \ldots, g_{t}$ is the event contingent maximum output of the firm. 


$$
P_{t}=\sum_{\lambda_{t+1}} \beta\left(\left(1+g_{t+1}\left(\lambda_{t+1}\right)\right)^{1-\gamma}\right) \pi_{t+1}\left(\lambda_{t+1} \mid \lambda_{t}\right)\left(P_{t+1}\left(\lambda_{t+1}\right)+1\right)
$$

The expected equity return conditional on the information available in time $t$ is given by:

$$
1+r_{t+1}=\sum_{\lambda_{t+1}} \frac{Q_{t+1}\left(\lambda_{t+1}\right)+e_{t+1}\left(\lambda_{t+1}\right)}{Q_{t}} \pi_{t+1}\left(\lambda_{t+1} \mid \lambda_{t}\right)
$$

Making

$$
\frac{Q_{t+1}+e_{t+1}}{Q_{t}}=\frac{e_{t+1}}{Q_{t}}\left(1+\frac{Q_{t+1}}{e_{t+1}}\right)
$$

Multiplying and dividing the above expression by $e_{t}$ :

$$
1+r_{t+1}=\sum_{\lambda_{t+1}}\left(1+g_{t+1}\left(\lambda_{t+1}\right)\right) \pi_{t+1}\left(\lambda_{t+1} \mid \lambda_{t}\right) \frac{1+P_{t+1}\left(\lambda_{t+1}\right)}{P_{t}}
$$

To obtain the risk-free rate note that (5) allows us to write, for $m=r$ or $m=r_{f} \quad\left(r_{f}\right.$ standing for the risk-free rate):

$$
1=\sum_{\lambda_{t+1}} \beta \frac{u^{\prime}\left(c_{t+1}\left(\lambda_{t+1}\right)\right)}{u^{\prime}\left(c_{t}\right)}\left(1+m_{t+1}\right) \pi_{t+1}\left(\lambda_{t+1} \mid \lambda_{t}\right)
$$

From which we get (also conditional on the information set available at time $t$, and noticing that by definition $r_{f_{\mathrm{t}}}$ does not depend on the realization of $\lambda_{t+1}$ ):

$$
1+r_{f_{t+1}}=\frac{1}{\beta \sum_{\lambda_{t+1}}\left(1+g_{t+1}\left(\lambda_{t+1}\right)\right)^{-\gamma} \pi_{t+1}\left(\lambda_{t+1} \mid \lambda_{t}\right)}
$$

\section{EXISTENCE OF THE EXPECTED UTILITY}

As pointed out by Mehra and Prescott (1985, p. 151), the introduction of nonstationarity in Lucas's (1978) model requires, among other things, verifying if the conditions under which the expected utility exists are satisfied. The Proposition below, the proof of which Mehra and Prescott (1985, p. 151) refer the reader to Mehra and Prescott (1984), provides a direct way to check it.

Proposition 1 - (Mehra and Prescott, 1984): Suppose the preferences of the representative consumer are ordered over random paths by (1) and (3). Denote by $W$ the transition matrix of the (ergodic) Markov chain associated with $g_{t+1} \in\left\{g_{1}, g_{2}, \ldots, g_{N}\right\}, g_{i} \geq 0$ for all $i$ and all $t$ and suppose that $e_{0}>0$. Then, a necessary and sufficient condition for expected utility to exist is that the matrix $A$ with elements $a_{i, j}=\beta W_{i, j}\left(1+g_{j}\right)^{1-\gamma}$ obeys: 


$$
\lim _{m \rightarrow \infty} A^{m}=0
$$

Proof - See Mehra and Prescott (1984) or Mehra (1988).

Note that condition (10) is equivalent to the matrix $A$ having eigenvalues all of which lie within the unit circle in the complex plan.

An intuition of this result is easily obtained from the analysis of the deterministic case, in which, trivially, $E U(c)<\infty$ if and only if $\beta(1+g)^{1-\gamma}<1$. In the stochastic case, one has to consider all states attained by $g$. In particular, note that when $\gamma$ is very high (in an attempt of the researcher to obtain high equity premia with the model) one can easily have $\beta(1+g)^{1-\gamma}>1$ for values of $g$ slightly below zero. This can pose a problem for the fulfillment of condition (10).

Condition (10) is also sufficient to guarantee a unique positive solution tot the $n$ by $n$ system of linear equations (when $\mathrm{n}$ states are considered) given by (6).

\section{DATA}

The Brazilian data used in this work has a quarterly frequency and ranges from 1992:1 to 2004:2. This period was chosen because 1992:1 is the point after which the official quarterly consumption series derived from the quarterly GDP series calculated by FIBGE (Fundação Instituto Brasileiro de Geografia e Estatística) and by the IPEA (Instituto Brasileiro de Pesquisa Econômica Aplicada) is available. The consumption series is provided by Macrodados.

Population data are from the FIBGE. For the two first quarters of 1994 population data were extrapolated under the assumption that the rate for 2004 was the same as the one for 2003. Within each year the series was quarterly interpolated assuming a log-linear growth.

The price index used to deflate consumption and to obtain real interest rates was the INPC (Índice Nacional de Preços ao Consumidor) provided by the FIBGE. The Selic (Sistema Especial de Liquidação e Custódia) interbank rate was used to generate the "risk-free" rate, and the return of the IBOVESPA index to generate the equity rate (a claim to the stochastic endowment). Both were deflated by the inflation rate calculated using the INPC. The source of the Selic and of the FGV-100 was the databank of the IBRE (Instituto Brasileiro de Economia da Fundação Getulio Vargas).

Table 1 summarizes the data used by different authors, including Prescott and Mehra for the US and Sampaio (2002), Domingues and Rodrigues (2002), Issler and Piqueira (2000, 2002), Alencar (2002) and Cysne (this work) for Brazil. 
Table 1 - Data (\%) on per.cap. cons. growth (g) and real returns

\begin{tabular}{llrrrrrrr}
\hline & Range/Per & $\mathrm{av}(\mathrm{g})$ & $\mathrm{st}(\mathrm{g})$ & $\mathrm{av}(\mathrm{r})$ & $\mathrm{st}(\mathrm{r})$ & $\mathrm{av}(\mathrm{rf})$ & $\mathrm{st}(\mathrm{rf})$ & \multicolumn{1}{c}{ e.p. } \\
\hline M/P (US) & $1889-78 \mathrm{~A}$ & 1.83 & 3.57 & 6.98 & 16.54 & 0.80 & 5.67 & 6.18 \\
Sampaio & $1980-98 \mathrm{Q}$ & 2.02 & 7.20 & 29.13 & 29.30 & 7.82 & 9.70 & 21.31 \\
B./D. & $1986-98 \mathrm{Q}$ & 0.80 & 6.80 & 24.21 & 31.42 & 13.96 & 6.28 & 10.25 \\
I./P. & $1975-94 \mathrm{~A}$ & - & - & - & - & - & - & 29.06 \\
Alencar & $1980-98 \mathrm{Q}$ & 1.61 & 2.2 & 28.65 & 29.1 & 7.40 & 5.70 & 21.25 \\
Cysne & $1992-04 \mathrm{Q}$ & 3.12 & 4.80 & 31.33 & 24.89 & 15.41 & 4.82 & 15.92 \\
\hline
\end{tabular}

av $=$ average, $\mathrm{st}=$ st. dev., $\mathrm{r}=$ equity rate, $\mathrm{rf}=$ risk-free rate, e.p. $=$ equity premium

$\mathrm{Q}=$ Quaterly, A = annual, Per = Periodicity, M. P = Mehra and Prescott (Table 1, p. 147)

B. $/$ D. = Bonomo and Domingues (Tables 1 and 2, p. 106).

I. /P. = Issler and Piqueira (p. 234 of I./P. (2000)). Data for Alencar comes from Table 2, p. 128 and for Sampaio from Table 1, p. 194.

All data regarding consumption growth, except the enters for Alencar, who only reports seasonally adjusted averages, are non-seasonally adjusted. Standard deviations are calculated under the periodicity of the data shown in column 2. All averages are expressed in annual terms using compounded rates. The equity premia are also annual and correspond simply to the difference between the respective equity and risk-free rates. All Brazilian authors calculate the mean return on equities using the IBOVESPA (Índice da Bolsa de Valores do Estado de São Paulo).

In Table 1, concerning the Brazilian economy, this work (last row in Table 1) presents the highest value of the per capita consumption growth. This is consistent with the fact that after the Real Plan there were high current account deficits, fostering consumption temporarily. The standard deviation of 0.048 (of consumption growth) is higher than the one reported by Mehra and Prescott (1982) for the US time series (0.036) But lower than the ones reported by Sampaio (0.072)) and by Bonomo and Domingues (0.068), for Brazil. This reflects the fact that these previous studies using Brazilian data included a larger share of the period in which inflation was higher. Relatively to the data I present here, they do not include the 1998-2004 low-inflation period.

This work also presents the highest risk-free rate $(15.41 \%)$ a consequence of the fact that after the Real Plan high interest rates were used to control the residual inflationary pressures. Last, note that the equity premium calculated here $(15.92 \%)$ is between the one calculated by Bonomo and Domingues (10.25\%) and those calculated by Issler and Piqueira (29.06\%) and by Sampaio $(21.31 \%)$.

Table 2 below presents the data in a way close to the one Mehra and Prescott (1985, Table 1) and Kocherlakota (1996, Table 1) did in their respective works:

Table 2 - Sample averages and covariance matrix of the equity rate $(1+r)$ the risk-free rate $(1+\mathrm{rf})$ and real per-capita consumption growth $(1+\mathrm{g})$

Sumary Statistics, Brazilian Data, 1992:1-2004:2

\begin{tabular}{lcrrr}
\hline & Mean & $1+r$ & $1+r f$ & $1+g$ \\
\hline $1+r$ & 1.07052 & 0.06193 & -0.00330 & 0.00208 \\
$1+r f$ & 1.03648 & -0.00330 & 0.00232 & -0.00032 \\
$1+g$ & 1.00770 & 0.00208 & -0.00032 & 0.00230 \\
\hline
\end{tabular}

The numbers in the first column of Table 2 correspond to the averages presented in the last row of Table 1 . However, in Table 1 they are expressed in an annual and percentage basis, whereas 
Table 2 presents them in a quarterly and decimal basis. The quarterly standard deviations reported in the last row of Table 1 can also be obtained from Table 2.

Note that, as it happens with the data reported in Mehra and Prescott (1985), the sample covariance of consumption growth and the return on equity $(0.00208)$ is higher than the sample covariance on consumption growth and the return on the risk-free asset $(-0.00032){ }^{11}$ This implies that the model we have seen in the last section does account for the fact that the return on equity (which pays more when consumption is higher) is observed to command a certain premium over the return on the risk-free rate. We shall see, though, that although qualitatively right, the CCAPM model is not able to provide a satisfactory quantitative rationalization for the equity premium found in the Brazilian data.

\section{EMPIRICAL RESULTS}

\section{1 Preliminary analysis under lognormality}

Before calibrating a general-equilibrium model as in Mehra and Prescott (1985), I investigate the existence an equity premium puzzle assuming lognormality of returns.

The expressions for asset returns under lognormality are well known in the literature (see, e.g. Hansen and Singleton, 1983; or Ljungqvist and Sargent, 2002), being included here just for completeness.

Suppose that consumption growth, the equity return (r) and the risk-free return follow the equations:

$$
1+k_{t+1}=(1+\bar{k}) \exp \left(\varepsilon_{k, t+1}-\sigma_{k}^{2} / 2\right), \text { for } k=g, k=r \text { or } k=r_{f}
$$

with $\left\{\varepsilon_{g, t+1}, \varepsilon_{r, t+1}, \varepsilon_{r_{f}, t+1}\right\}$ jointly normally distributed with zero means and variances $\left\{\sigma_{c}^{2}\right.$, $\left.\sigma_{r}^{2}, \sigma_{r_{f}}^{2}\right\}$. By using the fact that the moment generating function of a standard normal variable $\left(E(\exp (\tau Z))\right.$ is equal to $\exp \left(\tau^{2} / 2\right)$ one easily concludes that the expected value of $1+k_{t+1}$ in (11) is $\bar{k}$. This allows for an economic interpretation of (11) that is used below.

From equations (5) and (3), applying the law of iterated expectations:

$$
1=\beta E\left[\left(1+g_{t+1}\right)^{-\gamma}\left(1+m_{t+1}\right)\right], \quad \text { for } m=r \text { or } m=r_{f}
$$

Using (11) in (12), for $m=r$ or $m=r_{f}$ :

$$
1=(1+\bar{g})^{-\gamma}(1+\bar{m}) \beta E\left\{\exp \left[\left(\varepsilon_{m, t+1}-\sigma_{m}^{2} / 2\right)-\gamma\left(\varepsilon_{g, t+1}-\sigma_{g}^{2} / 2\right)\right]\right\}
$$

Since the variable between brackets is a normal variable with mean $-\sigma_{m}^{2} / 2+\gamma \sigma_{g}^{2} / 2$ and variance $\sigma_{m}^{2}+\gamma^{2} \sigma_{g}^{2}+2 \gamma \operatorname{cov}\left(\varepsilon_{m}, \varepsilon_{g}\right)$, using again the result above for the moment generating function of a standard normal variable (for $m=r$ or $m=r_{f}$ :

11 In the population, by definition, this value is equal to zero. 


$$
1=(1+\bar{g})^{-\gamma}(1+\bar{m}) \beta\left[\exp \left((1+\gamma) \gamma \sigma_{g}^{2} / 2-\gamma \operatorname{cov}\left(\varepsilon_{g}, \varepsilon_{m}\right)\right)\right]
$$

Taking logarithms on both members of (14):

$$
\log (1+\bar{m})=-\log \beta+\gamma \log (1+\bar{g})-\gamma(1-\gamma) \frac{\sigma_{g}^{2}}{2}-\gamma \operatorname{cov}\left(\varepsilon_{g}, \varepsilon_{m}\right)
$$

Making for $m=r$ and $m=r_{f}$ and above and and subtracting the resulting expressions:

$$
\log (1+\bar{r})-\log \left(1+\bar{r}_{f}\right)=\gamma\left(\operatorname{cov}\left(\varepsilon_{g}, \varepsilon_{r}\right)-\operatorname{cov}\left(\varepsilon_{g}, \varepsilon_{r_{f}}\right)\right)
$$

Since $\log (1+x) \simeq x$ for low (absolute) values of $x$ (16) allows us to use the sample values of $\operatorname{cov}\left(\varepsilon_{g}, \varepsilon_{r}\right), \operatorname{cov}\left(\varepsilon_{g}, \varepsilon_{r_{f}}\right)$, and the means of $r$ and $r_{f}$, in order to obtain the implied risk-aversion parameter $\gamma$. Approximating these covariances with the values of Table 2 , we get $\gamma=14.15$ or directly from the values of Table $3, \gamma=15.8$. One can also use the fact that the populational value of $\operatorname{cov}\left(\varepsilon_{g}, \varepsilon_{r_{f}}\right)$ is equal to zero, to obtain even higher values for $\gamma$ (16.36 and 19.12, respectively). In any case, it is clear form the data the existence of an EPP (since $\gamma>10$ is not acceptable as a reasonable range for the parameter $\gamma$ ).

\section{Table 3 - Covariance matrix using logarithms}

Covariance Matrix using Logarithms, Brazilian Data, 1992:1-2004:2

\begin{tabular}{lccc}
\hline & $\log (1+r)$ & $\log (1+r f)$ & $\log (1+g)$ \\
\hline $\log (1+r)$ & 0.05647 & -0.00322 & 0.00178 \\
$\log (1+r f)$ & -0.00322 & 0.00270 & -0.00037 \\
$\log (1+g)$ & 0.00178 & -0.00037 & 0.00229 \\
\hline
\end{tabular}

\section{2 Existence and calibration}

Since the calculations above relied on the assumption of lognormality, the conclusions may have resulted from this hypothesis, rather than from the empirical failure of the underlying model. In this subsection I abandon the hypothesis of lognormality and re-investigate the existence of an EPP under another set of assumptions.

I assume that real per-capita consumption growth $(g)$ follows a linear stochastic difference equation driven by a Gaussian disturbance, and that it can be reasonably modeled by a stationary $A R(1)$ process:

$$
g_{t}=b g_{t-1}+\varepsilon_{t}
$$

where $\varepsilon$ is a normal random variable with mean $a$.

Using (17) and the value of $b$ estimated from the sample data, one concludes that $\varepsilon_{t}$ has an average equal to 1.0016 and a standard deviation of 0.0480 Based on these data, I generate an approximation of the initial problem using ten different states for $g$ and a transition matrix $T$ of the approximating discrete-state Markov chain. 
The minimum and maximum values of the series of consumption growth are 0.9065 and 1.1016 , respectively. In the discrete-state approximation, such values are, respectively, 0.91 and $1.10 .{ }^{12}$ The states and the stationary probabilities are presented in Table 4.

Table 4 - Discrete-state Markov approximation

Stationary Probabilities (S.P.) and States of Per-Capta Real Consumption Growth

\begin{tabular}{lcc}
\hline & S.P. & States \\
\hline 1 & 0.03772 & 0.91177 \\
2 & 0.05349 & 0.93309 \\
3 & 0.09582 & 0.95441 \\
4 & 0.14133 & 0.97572 \\
5 & 0.17164 & 0.99704 \\
6 & 0.17164 & 1.01836 \\
7 & 0.14133 & 1.03967 \\
8 & 0.09582 & 1.06099 \\
9 & 0.05349 & 1.08231 \\
10 & 0.03772 & 1.10362 \\
\hline
\end{tabular}

\section{- Checking the Existence of an Expected Utility}

Before starting the simulations, it is crucial to check if, under the parameter values used in the problem, the necessary and sufficient conditions for the existence of an expected utility function are satisfied. This is done with the help of Proposition 1. The calculations using beta, the transition matrix and the ten states of consumption growth show that Proposition 1 is satisfied for the values of the gammas used in the simulations (from 2 to 6 ) but not necessarily for $\gamma>7$ (when $\beta=$ $0.995)$ or $\gamma>9$ (when $\beta=0.9740$ ).

The fact that the series of real per capita consumption growth used here has a higher average and a lower standard deviation than the ones used by Sampaio (2002) and by Bonomo and Domingues (2002) plays an important role in the existence of the expected utility (an inspection of condition (10) makes this point clear).

\section{- Calibration}

The calibration I carry out in this section has the advantage, when compared with those reported by Sampaio, and by Bonomo and Domingues, of approximating the consumption series with ten states, rather than just two.

The equity premium implied by the model is generated in the following way. First, the continuous state Markov chain is approximated by a ten-state Markov chain, as detailed above. Second, the transition matrix is used to simulate a time series of length 15000 for the states assumed by the Markov chain. Third, for each state, different values of the parameters $(\beta, \gamma)$ and (6) are used to calculate the price/dividend ratios. Fourth, such price-dividend ratios are used to calculate, also for each state, the return on equity, the risk-free rate and the equity premium. In this step I used (7), (9), and the fact that the equity premium is defined as $r-r_{f}$. Fifth, the 15000 states assumed by the Markov chain are employed to generate time series of $r, r_{f}$ and the equity premium. Sixth, I

12 The Markov chain implied by the data and its discrete-state approximation have also been compared regarding the implied firstorder correlation coefficient and the implied standard deviation of the series in order to get the best possible approximation. 
take the averages of each one of these series to obtain the equity return, the risk free rate and the equity premium generated by the model. ${ }^{13}$

The results of these steps are presented in Table 5.

Table 5 - Results of the simulation of the model based on the parameters derived from the 1992:1-2004:2 sample

Risky Return For Different Betas (Rows) and Gammas (Columns) =

\begin{tabular}{lccccc}
\hline & 2 & 3 & 4 & 5 & 6 \\
\hline .995 & 1.01838 & 1.02183 & 1.02309 & 1.02214 & 1.01899 \\
.9740 & 1.04034 & 1.04386 & 1.04515 & 1.04418 & 1.04096 \\
\hline
\end{tabular}

Risky-Free Rate For Different Betas (Rows) and Gammas (Columns) =

\begin{tabular}{lccccc}
\hline & 2 & 3 & 4 & 5 & 6 \\
\hline .995 & 1.01402 & 1.01527 & 1.01433 & 1.01121 & 1.00592 \\
.9740 & 1.03589 & 1.03716 & 1.03620 & 1.03301 & 1.02761
\end{tabular}

Equity Premia for Different Betas (Rows) and Gammas (Columns) =

\begin{tabular}{cccccc}
\hline & 2 & 3 & 4 & 5 & 6 \\
\hline .995 & 0.00435 & 0.00656 & 0.00876 & 0.01093 & 0.01307 \\
.9740 & 0.00445 & 0.00670 & 0.00895 & 0.01117 & 0.01336 \\
\hline
\end{tabular}

Note in Table 5 that both the equity return and the risky-free rate decrease for high values of gamma. Under deterministic growth, interest rates vary positively with the risk aversion parameter when consumption-growth rates are strictly positive (equation (15) with $m=r_{f}$ makes this point clear). When the variance of consumption growth is not zero, though, this rate tends to become a negative function of $\gamma$ when this parameter assumes higher values (see equation (15) once more) As one can observe from Table 4, states 1 to 5 considered in the simulations are characterized by negative rates of growth of consumption. For these reasons, one can get risk-free rates decreasing with the value of gamma.

From Table 1 or from Table 2, the quarterly equity return for the 1992:01-2004:2 period should run around $7.052 \%$, and the risk-free return around $3.648 \%$, generating a quarterly equity premium around $3.40 \%$. From Table 5 , the maximum equity premium generated by the model happens for $\beta=0.974$ and $\gamma=6$, and is equal to $1.34 \%$. This result confirms the preliminary calculations carried out under the assumption of lognormality, concluding that there is an EPP in Brazil.

In section 7 I check if this puzzle remains under more elaborate utility functions.

When $\beta=0.974$, the quarterly risk-free rate which emerges from the sample is generated for values of the relative risk-aversion parameter between two and four. Since these are considered to be reasonable parameters for $\gamma$, I find no risk-free-rate puzzle as the one identified by Weil (1989) for the United States. Neither an "inverted risk-free rate puzzle", as pointed out by Bonomo and Domingues (2002).

13 Since the Markov chain under consideration is ergodic, the state space is compact and the transition function defined by an $n$ by $n$ stochastic matrix defines a stable conditional operator (sometimes dubbed as an operator with the "Feller property"), step 6 is a.e.- equivalent, by the strong law of large numbers, to obtaining the averages of each variable using the stationary probabilities implied by the respective Markov chain (see, e.g., theorem 14.7 in Stokey, Lucas and Prescott, 1989, p. 425). 


\section{CONTRASTING THE RESULTS WITH SOME PREVIOUS WORKS}

In section 5 I have found evidence of the existence of an EPP in the Brazilian data, both under a lognormal approximation and in the calibration exercise using Brazilian 1992:1-2004:2 quarterly data.

In contrast with this result, Sampaio (2002, p. 99), using nonseasonally adjusted quarterly data ranging from 1980:1 to 1998:2, finds that the first moments of Brazilian data can be obtained using Mehra and Prescott's model for values of the risk aversion parameter $(\gamma)$ and of the time-discount parameter $(\beta)$ equal to, respectively, 6.1 and 0.91 (quarterly). Sampaio (2002) concludes that, once these parameters are accepted as valid, there is no EPP in Brazil.

Also in contrast with the results obtained here, Bonomo (2002, p. 116) states that "there is no equity premium puzzle in Brazil", whereas Issler and Piqueira (2000) argue that "there is no equity premium puzzle for Brazil due to the great variation observed for the equity premium" (page 233).

Two main factors explain the discrepancies between my results and those of these authors. The first regards the difference in the data sets. The second is that, except for the case of Sampaio (2002), the models and the empirical evaluations differ.

The data set used here differs from the data set used in these works not only because the time periods are different, but also because the consumption series are not the same. I use official quarterly IPEA/FIBGE/Macrodados's consumption data, including non-durables and durables, whereas Soriano, Sampaio (2002) and Bonomo and Rodrigues (2002) (see page 81 in Bonomo, 2002) use a private consumption series produced by Soriano, which excludes durables.

Regarding the models, Bonomo and Domingues use a Markov Switching model, whereas Issler and Piqueira concentrate their analysis in checking the necessary (Euler) conditions implied by the standard asset pricing models.

\section{Redoing the calculations using the same data set, but under lognormality}

Here I use parameter values derived from the data set used by Sampaio and by Bonomo and Domingues to evaluate if the results obtained by these authors survive under the assumption of lognormality. In order to redo the approximate calculations under lognormality, one needs the equity premia, as well as the covariance between consumption growth and the returns on equities and on the risk-free asset. Such data are not directly available, since Sampaio (2002) and Bonomo and Rodrigues (2002) do not report the sample covariances.

However, since these authors use the same real consumption series as Alencar (see Bonomo, 2002, p. 81), and since the series of nominal returns are the same (IBOVESPA and Selic), I use the Table of variance/covariance for nonseasonally adjusted data published in Alencar (2002, p. 157, Table 9).

From this table, the difference between the covariance of consumption and the risky rate, and the covariance of consumption and the nonrisky rate, using quarterly data, is equal to 0.0004 . Sampaio (2002, p. 96, Table 2) reports a quarterly premium of 0.047 whereas Bonomo and Domingues (2002, p. 106, Table 1) report 0.02247. Using (16), such values imply a risk-aversion parameter $(\gamma)$ equal to, respectively, 1175.0 and $561.75 .{ }^{15}$ These values are highly above those regarded

14 Alencar (2002) cannot be used as a direct source for comparison, since this author uses seasonally adjusted data in almost all of his calculations.

15 Using a covariance with the risk-free return equal to zero does not improve the results significantly. The new numbers for gamma are now 671.4 and 321.0 respectively. 
as reasonable for the risk-aversion parameter, leading to the conclusion that, under the assumption of lognormality, repeating the conclusion I had reached with a different data set, there is an EPP in Brazil. This result contrasts with those obtained by Sampaio and by Bonomo and Domingues using the same data set, but without the assumption of lognormality. This may suggest that this assumption is not appropriate in this case.

\section{Maximum allowable range between states implied by the existence of the expected utility}

Sampaio (2002) uses the same basic model as the one I use here. For this reason, below I report some additional calculations based in his work. I conclude that the maximum possible range between states of consumption growth that Sampaio (2002) could use falls short of the range displayed in his data. This is a condition implied by (10), on the existence of the expected utility.

Sampaio does not report for which range of the parameter values he uses one could assure the existence of the expected utility function. This condition is particularly important in the Brazilian case, because of the relatively lower average and higher standard deviation ${ }^{16}$ of the real per-capita consumption growth (when compared to the US). These facts imply assigning relatively high probabilities to states in which real per-capita consumption decreases sharply, with $\beta(1+g)^{1-\gamma}$ assuming values that can be too high for the expected utility to exist.

Next, I rely on the parameter values and the number of states (equal to 2 ) reported by Sampaio (2002). Using the parameter values of Table 1 in Sampaio (2002, p. 94) of average consumption growth equal to 0.005 , standard deviation of consumption growth 0.072 and first-order autocorrelation -0.128 , a implied 2 - state Markov chain can be very conservatively (concerning the validity of Proposition 1$)^{17}$ approximated with the states, stationary probabilities and Transition Matrix given by Table 6.

Table 6 - Evalution of the existence of the expected utility in Sampaio (2002) (Eigenvalue higher than one implies nonexistence of expected utility)

Approximation of Stat.Prob. and States for $\mathrm{g}$ Using the Data of Sampaio (2002)

\begin{tabular}{lcc}
\hline & S.P. & States \\
\hline 1 & 0.50000 & 0.88260 \\
2 & 0.50000 & 1.12740 \\
\hline
\end{tabular}

Approximate 2-State Transition Matrix Using the Data of Sampaio (2002)

\begin{tabular}{ccc}
\hline & 1 & 2 \\
\hline 1 & 0.41317 & 0.58683 \\
2 & 0.58683 & 0.41317 \\
\hline
\end{tabular}

16 The data reported by Alencar (2002) cannot serve as a basis of comparison here because this author uses seasonally adjusted data.

17 The states that emerge from the matrix of Table 6 , after the due adjustment in the $y$-coordinate are made, are contained in the range shown in Figure 1 of Sampaio (2002, p. 94). Using more than 1.4 standard deviations (I have used 1.4 here) in the construction of the approximate state space reduces the chances that the condition of Proposition 1 is satisfied, thereby the reported conservativeness of the present calculations. 
Matrix of Propositon 1 Calculated Using Data the of Sampaio (2002)

\begin{tabular}{ccc}
\hline & $-----1----$ & $----2----$ \\
\hline$--1--$ & 0.71084 & 0.28971 \\
$--2-$ & 1.00962 & 0.20397 \\
\hline
\end{tabular}

Eigenvalue of Matrix A of Propositon 1 Calculated using Data the of Sampaio (2002)

\begin{tabular}{ll}
\hline & $---1----$ \\
\hline$--1--$ & 1.05467 \\
\hline
\end{tabular}

Note in Table 6 that the two states of the approximation of the rate of growth of the endowments, 0.88260 and 1.12740, both lie within the range displayed in Figure 1 of Sampaio (2002, p. 94) (bye the eye, the sample range in Figure 1 of Sampaio (2002) goes from 0.85 to 1.15). Moreover, the weighed mean of the approximating states, using the stationary probabilities, exactly coincides with 1.005, the sample value of the average rate of growth of consumption reported by this author.

Increasing the range of the approximation would be supported by the data but would make things worse in terms of the existence of an expected utility. The numbers used here, therefore, are conservative.

Table 6 also shows the values of the matrix $A$ in Proposition 1 , for $\gamma=-6.1$ and $\beta=0.91$ which are found by Sampaio as those for which there is no premium puzzle. The maximum absolute value of the eigenvalues of this matrix is equal to 1.0547 , implying that condition (10) is not satisfied.

An alternative calculation, probably closer to the way how this author may have worked, is inverting the procedure and obtaining the maximum possible range for the rates of consumption growth that still allow for the existence of an expected utility. The results are presented in Table 7. The new lower and upper bounds for the rate of consumption growth (respectively, 0.906 and 1.104), though, are farther away from the respective end points of the sample values displayed in Figure 1 in Sampaio (2002).

Table 7 - Calculation of the range under which the existence of expected utility in Sampaio (2002) can be insured

Constrained Approx.of Stat.Prob. and States for g using the Date of Sampaio (2002)

\begin{tabular}{lcc}
\hline & S.P. & States \\
\hline 1 & 0.50000 & 0.90600 \\
2 & 0.50000 & 1.10400 \\
\hline
\end{tabular}

Constrained Approximate 2-State Transition Matrix Using the Date of Sampaio (2002)

\begin{tabular}{ccc}
\hline & 1 & 2 \\
\hline 1 & 0.42957 & 0.57043 \\
2 & 0.57043 & 0.42957 \\
\hline
\end{tabular}


Constrained Matrix of Proposition 1 Calculated Using the Data of Sampaio (2002)

\begin{tabular}{lcc}
\hline & $----1---$ & $---2----$ \\
\hline$---1---$ & 0.64673 & 0.31340 \\
$----2---$ & 0.85879 & 0.23601
\end{tabular}

Eigenvalue of the Constrained Matrix A of Prop.1 Calc.Using the Data of Sampaio (2002)

\begin{tabular}{ll}
\hline & $----1---$ \\
\hline$---1---$ & 0.99933 \\
\hline
\end{tabular}

- Issler and Piqueira (2000, 2002)

The main purpose of Issler and Piqueira $(2000,2002)$ is not discussing the equity-premium puzzle (which is done only in the last pages), but to estimate structural parameters for the Brazilian economy under different types of utility functions. The comments below refer strictly to the question of the equity-premium puzzle.

Issler and Piqueira (2000, 2002) take differences in (8), for $m=r$ and $m=r_{f}$ and use the linearity of the conditional expectation to write the necessary condition for optimality:

$$
0=E_{t}\left[\beta \frac{u^{\prime}\left(c_{t+1}\left(\lambda_{t+1}\right)\right)}{u^{\prime}\left(c_{t}\right)}\left(r_{t+1}-r_{f_{t+1}}\right)\right]
$$

Next, the authors use the law of iterated expectations to get the (weaker) necessary condition:

$$
0=E\left[\beta \frac{u^{\prime}\left(c_{t+1}\left(\lambda_{t+1}\right)\right)}{u^{\prime}\left(c_{t}\right)}\left(r_{t+1}-r_{f_{t+1}}\right)\right]
$$

After making some distributional assumptions, the authors argue that one cannot reject the hypothesis that the right member of (19) is equal to zero, and conclude (page 233 in Isller and Piqueira, 2000) that "there is no equity premium puzzle for Brazil" and (page 234) that "there is no equity premium puzzle for Brazil because there is no equity premium either."

I interpret the writings of these authors as "we have not been able to reject the necessary conditions implied by the standard asset pricing model, and therefore we reject the hypothesis of there existing an equity premium based on the results we have so far."

Under this understanding, the best way to confront the results obtained here with those obtained by Issler and Piqueira $(2000,2002)$ would be through an empirical re-evaluation of the restrictions implied by the basic CCAPM model using the same data set I used here and the same methodology used by these authors. This is a possible suggestion for future research in the area.

\section{EMPIRICAL RESULTS WITH RECURSIVE UTILITY}

A restriction imposed by the class of preferences we have used so far is that the same parameter $(\gamma)$ assumes simultaneously the role of the coefficient of risk aversion and of the reciprocal of 
the elasticity of intertemporal substitution. This implies that aversion to uncertainty among states of nature is necessarily related to aversion to consumption variation over time. Epstein and Zin (1991) use Kreps-Porteus (1978) preferences, a class of preferences that avoids this problem. Their recursive utility can be stated as:

$$
V_{t}=\left((1-\delta) c_{t}^{1-\rho}+\delta\left(\Phi_{t} V_{t+1}\right)^{1-\rho}\right)^{\frac{1}{1-\rho}}, \quad \rho \neq 1,0<\delta<1
$$

where:

$$
\Phi_{t} V_{t+1}=E_{t}\left(V_{t+1}^{1-\alpha}\right)^{\frac{1}{1-\alpha}}
$$

Proceeding as before, the expected price/equity ratio is now given by:

$$
P_{t}^{e}=E_{t}\left(\delta\left(\frac{c_{t+1}}{c_{t}}\right)^{1-\rho}\left(\frac{V_{t+1}}{\Phi_{t} V_{t+1}}\right)^{\rho-\alpha}\left(1+P_{t+1}^{e}\right)\right)
$$

Making $W_{t}=V_{t} / e_{t}$ one has:

$$
P_{t}=E_{t}\left(\delta\left(g_{t+1}\right)^{1-\rho}\left(\frac{g_{t+1} W_{t+1}}{\Phi_{t}\left(g_{t+1} W_{t+1}\right)}\right)^{\rho-\alpha}\left(1+P_{t+1}^{e}\right)\right)
$$

Note that this formula is equivalent to (6), except for the presence of the term $\left(\frac{g_{t+1} W_{t+1}}{\Phi_{t}\left(g_{t+1} W_{t+1}\right)}\right)^{\rho-\alpha}$ on the right member and for the fact that $\rho$ is replacing $\gamma$ and $\delta$ is replacing $\beta$. The risk-free rate now reads:

$$
r_{f_{t}}=\frac{1}{E_{t}\left(\delta\left(g_{t+1}\right)^{-\rho}\left(\frac{g_{t+1} W_{t+1}}{\Phi_{t}\left(g_{t+1} W_{t+1}\right)}\right)^{\rho-\alpha}\right)}
$$

The equity rate is determined as before, using the new value of the price-dividend ratio. $\rho$ stands for the inverse of the elasticity of substitution, the same as gamma in the previous section. The risk aversion parameter here is now given by $\alpha$, thereby being completely independent of the elasticity of substitution $1 / \rho . \delta /(1-\delta)$ can be interpreted as the new time-discount parameter (the beta of the previous section).

I redo the previous calculations for $\rho=2$ and $\alpha=5,6$, in order to compare with the previous case. The results are shown in Table 8. 
Table 8 - Results with recursive utility

Rec.Utility, Risk Return For Rho $=2$ and Alpha $=5,8=$

\begin{tabular}{lll}
\hline & $----1----$ & $---2---$ \\
\hline$--1---$ & 1.03688 & 1.03346 \\
\hline
\end{tabular}

Rec.Utility, Risky-Free Rate For Rho=2 and Alpha=5,8 =

\begin{tabular}{lll}
\hline & $----1----$ & $---2---$ \\
\hline$---1---$ & 1.02604 & 1.01652 \\
\hline
\end{tabular}

Rec.Utility, Equity Premia For Rho=2 and Alpha=5,8 =

\begin{tabular}{lll}
\hline & $----1---$ & $---2----$ \\
\hline$---1---$ & 0.01084 & 0.01694 \\
\hline
\end{tabular}

As it is clear from the last row of Table 8, using recursive utility does not modify the fact that Mehra and Prescott's-like models are not able to satisfactorily rationalize the equity premium found in the Brazilian data. On the other hand, the risk-free rate that is generated by the model with $\rho=2$ and $\alpha=5$ is basically the same as the one observed in the sample. Again, there is no risk-free rate puzzle, as the one reported by Weil (1989) for the U.S., or "inverted risk-free rate puzzle”, as the one reported by Bonomo and Domingues (2002) for Brazil.

\section{CONCLUSIONS}

In this paper I have used 1992:1-2004:2 Brazilian quarterly data to evaluate the existence of an EPP. In contrast with some previous works in the Brazilian literature, I have concluded that the model used by Mehra and Prescott (1985), either with additive or recursive preferences, is not able to satisfactorily rationalize the equity premium observed in the Brazilian data.

Such a conclusion was obtained both under assumptions of lognormality or under simulations based on a discrete state approximation of the Markov process implied by the data. The model is able, though, to produce risk-free interest rates in agreement with those observed in Brazil.

In order to understand why my conclusions differed from those obtained by Sampaio and by Bonomo and Domingues, I have used the parameter values reported by these authors and tried to reproduce their conclusions under the assumption of lognormality of the consumption growth and of the returns on the assets. This implied the attainment of risk-aversion parameters outside the usually allowable range (1175.0 and 561.75), suggesting the existence of an EPP in Brazil. This result contrasts with those obtained by Sampaio and by Bonomo and Domingues using the same data set, suggesting that the lognormal approximation may be a poor approximation in this case.

I have also derived the maximum allowable range between states that Sampaio (who uses the same model I use here) could use to model consumption growth under the Mehra and Prescott methodology. The results have shown a range very inferior to the one displayed by his data. This last conclusion exemplifies a case, and is a consequence of the fact that the utility function may not exist (under the Mehra and Prescott methodolology) when one uses a small number of states to approximate a consumption-growth series with relatively high standard deviation (as it happens with 
Brazilian data) and tries to rationalize the EPP using values of the risk-aversion parameter that lie within the usually allowable range (0 to 10$)$, but are otherwise too high.

Finally, I have redone the calibrations using Kreps-Porteus (1978) preferences and have maintained my previous conclusion that the usual CCAPM models cannot satisfactorily rationalize the equity premium implicit in the Brazilian data, even though they are able to generate the risk-free interest rates found in Brazil.

\section{REFERENCES}

Alencar, A. S. Testando CCAPM através das fronteiras de volatilidade e da equação de Euler. In: Bonomo, M., (Ed.), Finanças aplicadas ao Brasil. Rio de Janeiro: Editora da Fundação Getulio Vargas, 2002, p. 119-161.

Allais O.; Nalpas, N. The equity premium puzzle: an evaluation of the French case. University of Paris I, 1999. Mimeo.

Bansal, R.; Coleman, J. W. A monetary explanation of the equity premium, term premium, and risk-free rate puzzles. Journal of Political Economy, v. 104, n. 6, p. 1135-71, December 1996.

Bonomo, M. A. (Ed.), Finanças aplicadas ao Brasil. Rio de Janeiro: Fundação Getulio Vargas, 2002.

Bonomo, M. A. C.; Domingues, G. B. Os puzzles invertidos no mercado brasileiro de ativos. In: Bonomo, M. (Ed.), Finanças aplicadas ao Brasil. Rio de Janeiro: Fundação Getulio Vargas, 2002, p. 105-120.

Breeden, D. An intertemporal asset pricing model with stochastic consumption and investment opportunities. Journal of Financial Economics, v. 7, n. 3, p. 265-296, September 1979.

Campbell, J. Y.; Cochrane, J. H. By force of habit: a consumption-based explanation of aggregate stock market behavior. Journal of Political Economy, v. 107, n. 2, p. 205-251, April 1999.

Browning, M.; Hansen, L. P.; Heckman, J. Micro data and general equilibrium models. Discussion Papers 99-10, University of Copenhagen. Institute of Economics, 1999.

Hansen, L. P.; Jagannathan, R. Implications of security market data for models of dynamic economies. Journal of Political Economy, 99, p. 225-62, 1991.

Canova, F.; Nicolo, G. The equity premium and the risk free rate: a cross country, cross maturity examination. Discussion Paper 1119, Centre for Economic Policy Research (CEPR), 1995.

Cecchetti, S. G.; Mark, N. Evaluating empirical tests of asset pricing models: alternative interpretations. The American Economic Review, v. 80, n. 2, 1990.

Constantinides, G. M. Habit formation: a resolution of the equity premium puzzle. Journal of Political Economy, v. 98, n. 3, p. 519-543, June 1990.

Constantinides, G. M.; Duffie, D. Asset pricing with heterogeneous consumers. Journal of Political Economy, v. 104, n. 2, p. 219-240, April 1996.

Davis, S. J.; Willen, P. Using financial assets to hedge labor income risk: estimating the benefits. Working Paper. Chicago, IL: University of Chicago, 2000.

Epstein, L. G.; Zin, S. E. Substitution, risk aversion, and the temporal behavior of consumption and asset returns: an empirical analysis. Journal of Political Economy, v. 99, n. 2, p. 263-286, April 1991.

Hansen L. P.; Singleton, K. J. Generalized instrumental variables estimation of nonlinear expectations models. Econometrica, v. 50, n. 5, p. 1269-1286, 1982.

Stochastic consumption, risk aversion, and the temporal behavior of asset returns. Journal of Political Economy, v. 91, n. 21, 1983.

Heaton, J.; Lucas, D. J. Evaluating the effects of incomplete markets on risk sharing and asset pricing. Journal of Political Economy, v. 104, n. 3, p. 443-487, June 1996. 
Issler, J. V.; Piqueira, N. S. Estimating relative risk aversion, the discount rate, and the intertemporal elasticity of substitution in consumption for Brazil using three types of utility functions. Brazilian Review of Econometrics, v. 20, n. 2, p. 201-239, 2000.

. Estimating relative risk aversion, the discount rate, and the intertemporal elasticity of substitution in consumption for Brazil using three types of utility functions. In: Bonomo, M. A. (Ed.), Finanças aplicadas ao Brasil. Rio de Janeiro: Fundação Getulio Vargas, 2002.

Iwata, K. Asset prices and consumption: the risk premium puzzle in Japan. Working Paper, Department of Advanced Social and International Studies, Komaba: University of Tokyo, 1996.

Kocherlakota, Narayana R. The equity premium: it's still a puzzle. Journal of Economic Literature, v. 34, n. 1, p. 42-71, 1996.

Kreps, D. M.; Porteus, E. L. Temporal resolution of uncertainty and dynamic choice theory. Econometrica, v. 46, n. 1, p. 185-200, 1978.

Ljungqvist, L.; Sargent, T. Recursive macroeconomic theory. Second edition. USA: MIT Press, 2002.

Lucas, R. E. Asset prices in an exchange economy. Econometrica, 46, p. 1429-1445, 1978.

McGrattan, E. R.; Prescott, E. C. Taxes, regulations, and asset prices. Working Paper N. 610, Federal Reserve Bank of Minneapolis, 2001.

Mehra, R. On the existence and representation of equilibrium in an economy with growth and nonstationary consumption. International Economic Review, v. 29, n. 1, February 1988.

. The equity premium: why is it a puzzle? Financial Analysts Journal, v. 59, n. 1, January/February 2003.

Mehra, R.; Prescott, E. C. Asset prices with nonstationary consumption. Working Paper, Graduate School of Business, NY: Columbia University, 1984.

. The equity premium: a puzzle. Journal of Monetary Economics, 15, p. 145-161, 1985.

Rietz, T. A. The equity risk premium: a solution. Journal of Monetary Economics, v. 22, n. 1, p. 17-131, July 1988.

Sampaio, F. S. Existe equity premium puzzle no Brazil? In: Bonomo, M. (Ed.), Finanças aplicadas ao Brasil. Rio de Janeiro: Editora da Fundação Getulio Vargas, 2002, p. 87-104.

Santomero, A. M.; Babbel, D. Financial markets, instruments, and institutions. Irwin Publications, 2005, 2/e.

Stokey, N. L.; Lucas Jr., Robert; Prescott, Edward C. (Contributor). Recursive methods in economic dynamics. Harvard University Press, 1989.

Weil, P. The equity premium and the risk-free rate puzzle. Journal of Monetary Economics, 24, p. 401-21, 1989.

Yoshino, J. A.; Catalão, A. B. The equity premium puzzle: Brasil e Estados Unidos. FEA-USP, Universidade de São Paulo, 2004. Mimeo. 